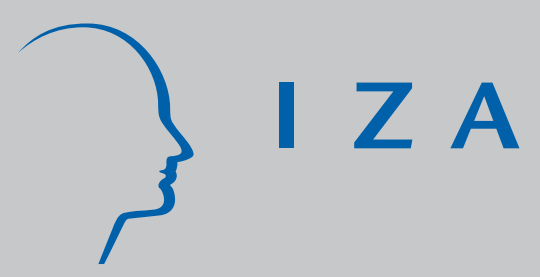

IZA DP No. 3335

What Is a Peer? The Role of Network Definitions in Estimation of Endogenous Peer Effects

Timothy J. Halliday

Sally Kwak

February 2008 


\title{
What Is a Peer? The Role of Network Definitions in Estimation of Endogenous Peer Effects
}

\author{
Timothy J. Halliday \\ University of Hawaii at Manoa \\ and IZA \\ Sally Kwak \\ University of Hawaii at Manoa
}

\section{Discussion Paper No. 3335 \\ February 2008}

\author{
IZA \\ P.O. Box 7240 \\ 53072 Bonn \\ Germany \\ Phone: +49-228-3894-0 \\ Fax: +49-228-3894-180 \\ E-mail: iza@iza.org
}

Any opinions expressed here are those of the author(s) and not those of IZA. Research published in this series may include views on policy, but the institute itself takes no institutional policy positions.

The Institute for the Study of Labor (IZA) in Bonn is a local and virtual international research center and a place of communication between science, politics and business. IZA is an independent nonprofit organization supported by Deutsche Post World Net. The center is associated with the University of Bonn and offers a stimulating research environment through its international network, workshops and conferences, data service, project support, research visits and doctoral program. IZA engages in (i) original and internationally competitive research in all fields of labor economics, (ii) development of policy concepts, and (iii) dissemination of research results and concepts to the interested public.

IZA Discussion Papers often represent preliminary work and are circulated to encourage discussion. Citation of such a paper should account for its provisional character. A revised version may be available directly from the author. 
IZA Discussion Paper No. 3335

February 2008

\section{ABSTRACT \\ What Is a Peer? The Role of Network Definitions in Estimation of Endogenous Peer Effects ${ }^{*}$}

We employ a standard identification strategy from the peer effects literature to investigate the importance of network definitions in estimation of endogenous peer effects. We use detailed information on friends in the Adolescent Longitudinal Health Survey (Add Health) to construct two network definitions that are less ad hoc than the school-grade cohorts commonly used in the educational peer effects literature. We demonstrate that accurate definitions of the peer network seriously impact estimation of peer effects. In particular, we show that peer effects estimates on educational achievement, smoking, sexual behavior, and drinking are substantially larger with our more detailed measures than with the school-grade cohorts. These results highlight the need to further understand how friendships form in order to fully understand implications for policy that alters the peer group mix at the classroom or cohort level.

JEL Classification: $\quad$ I12, I20

Keywords: $\quad$ peer effects, education, adolescent health

Corresponding author:

Timothy J. Halliday

Department of Economics

University of Hawai'i at Manoa

2424 Maile Way

Saunders Hall 533

Honolulu, HI 96822

USA

E-mail: halliday@hawaii.edu

\footnotetext{
* We would like to thank seminar participants at UH Manoa and the Berkeley Labor Lunch for useful comments.
} 


\section{Introduction}

The potential effect of peers and social networks on individual behavior is a source of debate in many policy contexts. Economists have explored effects of peers on school participation decisions (Cipollone and Rosolia, 2003; Gaviria and Raphael, 2001; Bobonis and Finan, 2006), on worker productivity (Mas and Moretti, 2006), on choice of medical school specialty (Arcidiacono and Nicholson, 2005), on utilization of prenatal care (Aizer and Currie, 2005), and on retirement savings behavior (Duflo and Saez, 2002) among others. Previous research addresses the difficult econometric issues in identifying social interactions. However, very few papers directly address the ad-hoc manner in which peer groups are often defined.

An informal sampling of the literature in educational peer effects shows the frequent use of school-grade cohorts as the peer group of interest (Appendix A). However, it is unclear whether school-grade cohorts are the true peer group in operation or whether they merely influence the composition of closer friendship ties, which in turn affect peer outcomes. There are relatively few examples of papers that do not use school-grade cohorts or classrooms as the relevant peer group. One important exception is work by Carell, Fullerton, Gilchrist and West (2007) which uses random assignment to squadrons in the U.S. Air Force Academy to identify peer effects. In this work, the use of the squadron as the relevant peer group is carefully justified. Foster (2006) also uses an alternative definition of peer group, "all students residing in rooms that are on the same wing of a residence hall floor as the given student," though it is less clear why this should be the correct peer group of interest. A fuller discussion of the policy relevance of such findings follows below.

In this paper, we use the Adolescent Health Survey (Add Health Data) to explore the way in which peer group definitions impact estimates of the effect of adolescent peers on propensities to achieve good grades in school, to smoke, to engage in risky sexual behavior and to drink. Our contributions are threefold. The first contribution is the estimation of peer effects using both self- 
reported friend groups and school-grade cohorts. Comparisons of estimates across network definitions within the same dataset have not yet been made in the literature. Our results suggest that behavior observed at the school-grade cohort level is essentially a reduced-form approximation of a two-step process in which students first sort themselves into peer groups and then behave in such a way that determines an outcome. As such, we argue the use of school-grade cohorts to estimate the full influence of peers on outcomes is flawed.

We further claim that the use of school-grade cohorts can lead to a number of serious econometric issues including: omitted variables bias, collinearity and weak instruments. For example, if the researcher specifies the network as a school-grade cohort, but does not address the substantial heterogeneity across schools by including a set of school dummy variables, the estimate of the endogenous peer effects will be contaminated by (among other factors) omitted school characteristics that are both positively correlated with the network's and the pupil's behavior. In the language of Manksi (1995), these are called correlated effects. Researchers often address this source of bias by controlling for fixed school characteristics but in so doing, reduce much of the variation in the network behavior.

Because of this collinearity between the network's behavior and the school fixed effects, we show that it is difficult to detect endogenous effects even if they are present. We believe this may be why some recent studies such as Foster (2006) and Arcidiacono and Nicholson (2005) fail to detect a relationship between own behavior and network background characteristics. Furthermore, school fixed effects may address the problem of correlated effects, but they do not address simultaneity bias, also known as "the reflection problem" (Manski, 2005). To address this problem, researchers often use instrumental variables analysis. However, if the instrument is specified at the level of the school-grade cohort and if school-fixed effects are included in the estimations, the instrument will be weak. We provide evidence for this assertion. 
The second contribution of this paper is that it is the first (of which we are aware) to explore alternative definitions of peer groups in a nationally representative sample of adolescents. Two papers which use alternative definitions of peer group, Sacerdote (2001), Kremer and Levy (2003), and Duncan et al (2005), use roommates at Dartmouth college and two large state universities as the peer groups of interest. The two papers cited above, Carrell et al (2007) and Foster (2006), examine a sample of college students at two select institutions of higher education, the U.S. Air Force Academy and the University of Maryland respectively. However, no such papers study alternative definitions of peer groups on nationally representative samples of adolescents. The third contribution is to add to a relatively sparse literature that examines the effect of peers on important adolescent health outcomes such as drinking, smoking, and sexual behavior. Hanushek et al (2003) notes, "due to limited outcome measures... all empirical work examines academic achievement. Many of the policy discussions and parental concerns focus on other outcomes including teen pregnancy, drug use... to name a few." Our paper fills this gap in the literature.

Unfortunately, the effort to estimate peer effects is complicated by a number of other empirical issues as well. These empirical issues are outlined most comprehensively in Charles Manski's seminal work (1995) and we borrow heavily from his framework to model our problem in the following sections. In particular, it is difficult to separately identify the endogenous peer effect from other contextual and correlated effects. For example, when we observe correlations between individual and peer group GPA's, we are not always able to discern whether this correlation arises because 1) individuals who get good grades tend to associate with friends who also get good grades, or 2) individuals are influenced by their peers to get good grades. If the first, policy affects only the outcomes of the targeted individuals, if the second, policy has an impact on outcomes that is magnified by a social multiplier effect. Though we focus on the errors in estimation brought on by defining the peer group incorrectly, we also address these identification issues. 
Policy Implications

Educational policymakers are particularly interested in quantifying the effect of peers on adolescent behavior because of the long-term consequences of adolescent choices. As a result, the existence and size of peer effects hold important implications in a number of educational policy debates. ${ }^{1}$ In comparing these effects across varying definitions of 'peer group', we see that definitions are important to identifying correct effects for policy. We show that peer effects estimates on educational achievement, smoking, sexual behavior, and drinking are consistently and substantially larger and more precisely estimated with our more detailed measures than with the school-grade cohorts. In fact, even when effects of school-grade cohorts are zero, we find significant effects of friends on outcomes. Because we believe the most significant peer influences occur at the level of individual friendship ties, estimates of school-grade cohort effects do not capture the true parameter of interest. Rather, correct estimates of peer influence depend on two separate effects: the sorting of students into friend groups and the subsequent effect of friends on their peers. The use of school-grade cohorts leads to reduced-form estimates of these combined effects. Our paper focuses on the second effect; we find significant friend effects even in the presence of much weaker and often non-existent school-grade cohort effects.

These results highlight the need to further understand how friendships form in order to fully understand implications for policy that alters the peer group mix at the classroom or cohort level. It

\footnotetext{
1 Discussions on school choice policies address concerns over the influence of high-performing students on their lowerperforming counterparts and vice versa (for example, Cullen, Jacob, and Levitt, 2006). Both proponents and detractors of tracking policies within elementary and secondary schools ask these same questions (for example, Lefgren, 2004). The current debate over optimal school grade configurations asks whether or not older students have a negative impact on the educational outcomes of their younger peers (Bedard and Do, 2005). Discussions of single-sex versus coeducational classrooms involve questions of gender-based peer effects (Whitmore, 2005). And special education policymakers express concern over the effect of special education peers on the educational outcomes of their regular education counterparts and vice versa (for example, Hanushek, et al 2002). Furthermore, an important current strand of research in public policy, child psychology, and education documents concern that treatments which isolate and segregate youths engaged in risky behaviors may exacerbate the problem if these teens teach, encourage and reward further deviant behavior in their peers (for example, Dodge, Dishion, Lansford, 2006).
} 
may be true that school-grade cohorts are the policy tool over which policymakers have the most control. However, if the most significant peer influences occur at the level of individual friendship ties, the efficacy of educational policies that change the mix of peers at the school-grade cohort level will ultimately depend on how students sort into friend groups. For example, suppose students sort into friend groups based solely on geographical proximity. Then friend groups consist of students who ride the same bus together, who sit next to each other in the same classrooms, or who eat lunch together in the same period. In such a setting, a school policy that sorts students into classrooms or school-grade cohorts affects student outcomes. On the other hand, if students choose friends based solely on gender or ethnicity, a shared family background, or shared interests without regard to proximity, policy that sorts students into classrooms or school-grade cohorts has a diminished or non-existent impact on student outcomes.

The remainder of the paper is organized as follows: section II describes the data, section III summarizes the empirical approach and its accompanying estimation issues, and section IV describes the construction of peer group definitions in detail. In section $\mathrm{V}$ we discuss the main findings of the paper, and section VI concludes.

\section{Data}

We use data from the National Longitudinal Adolescent Health Survey (Add Health). The Add Health survey was conducted by the Carolina Population Center and is available for a nationally representative sample of students who were in seventh through twelfth grades in 1994 . We use data from two waves of the survey: Wave I was conducted in 1994-95 and Wave II in 1996. The Wave I survey consists of an In-School questionnaire which was filled out by 90,118 students in 145 schools in 80 communities. A subset of 20,745 students was then chosen for an in-depth In-Home survey. The Wave II survey includes an In-Home questionnaire which was completed by 14,738 students. 
The 145 schools in the Wave I survey consist of pairs of sister schools. That is, if a particular high school was included in the survey, the corresponding feeder junior high or middle school was also included. If a school spanning seventh through twelfth grades was chosen for the survey, no sister school was included.

Students in each wave were asked detailed questions about their choices to smoke, drink alcohol, and engage in risky sexual behaviors. They were also asked about their performance in school, including grades in English, math, science, and social studies. Using this information, we construct four variables: the number of cigarettes the student smokes in an average day, the number of times in the past year the student drank alcohol, whether or not the student has ever had sex, and the student's average grade point average. ${ }^{2}$ We measure the effects of peers on these four outcome variables. Descriptive statistics and sample sizes for the outcome variables and all other control variables are reported in Table $1 \mathrm{~A}$.

\section{Peer Networks}

The Add Health survey is particularly useful for our purposes because of the extensive data on friendship networks. Using this information, we are able to define peer groups more accurately and precisely than has been possible in many previous studies. In each of the surveys, students are asked to nominate five female friends and five male friends. In almost all cases, students report fewer than five male and five female friends indicating that they are not constrained in their choice of friends in their network by the ten-friend limit. These friend nominations include both friends in the same school as well as friends from outside of school. Because we do not have information on

\footnotetext{
2 The variable for average number of drinks per year is a categorical variable ranging from 0 for never to 6 for nearly every day or every day. We transform it to be a cardinal variable which takes on a value of 0 for "never drank", 1.5 for " 1 or 2 days in the past month," 7 for " 3 to 12 times in the past 12 months," 30 for "two to three times a month," 78 for "1 or 2 days per week," 208 for " 3 to 5 days per week," and 365 for "nearly every day." The recoded variable counts how many days the person drank alcohol in the past year. The grade point average is calculated by averaging grades from English, math, science, and social studies using a four point scale.
} 
friends outside of the respondent's school, we are unable to include them in our measures of average peer group behavior. However, the vast majority of friend nominations are to other students in the same school; on average only $15 \%$ of friend nominations are to friends outside of the respondent's school. There are also sizeable numbers of nominations to friends that are not found on the school rosters. In the In-School Wave I sample, for example, approximately eight percent of nominations are not found on the school rosters. This may be due to the mixed use of nicknames and official names, students who are new to the school, or errors in school records. We drop these observations from the analysis. All in all, we are left with 21,118 observations in the In-Home sample and 66,308 observations in the In-School sample.

The first and third rows of Table $1 \mathrm{~B}$ report summary statistics on the average number of friends in the Add-Health peer networks for the In-Home and In-School files. We do not include friends who attend other schools or whose information can not be found in the surveys. The average number of nominations in the In-Home and In-School data is 1.27 and 3.91 respectively. Because the In-Home file surveys a substantially smaller subset of the In-School population, the data for a given respondent's nominated friend is often not available in the In-Home sample. This is the primary reason for the discrepancy in the average size of the In-Home peer groups versus the InSchool peer groups.

\section{Estimation}

\section{Identification Issues}

Manski (1995) notes one approach to estimating peer effects is given by:

$$
y=\alpha+\beta E[y \mid x]+E[w \mid x]^{\prime} \gamma+w^{\prime} \lambda+u,
$$


where $y$ is the outcome of interest (GPA, smoking, sexual behavior, or drinking), $x$ is a vector of group characteristics, $w$ is a vector of individual characteristics, and $u$ is an idiosyncratic error term. Following Manksi (1995), we assume that $E[u \mid x, w]=x^{\prime} \delta$ and rewrite equation (1) as follows:

$$
E[y \mid x, w]=\alpha+\beta E[y \mid x]+E[w \mid x]^{\prime} \gamma+w^{\prime} \lambda+x^{\prime} \delta
$$

We observe that the behavior of individuals in groups can be conceptually separated into three strands of effects: contextual effects, correlated effects, and endogenous peer effects. Contextual effects $(\gamma \neq 0)$ arise when "the propensity of an individual to behave in some way varies with the distribution of background characteristics in the group". For example, the tendency of student achievement to vary with socioeconomic background would be considered a contextual effect. Correlated effects $(\delta \neq 0)$ describe "the propensity of individuals in the same group to behave similarly because they face similar institutional environments or have similar individual characteristics". For example, students in the same school may tend to achieve similarly because they face the same teachers and curriculum. Endogenous peer effects $(\beta \neq 0)$ refer to the propensity of an individual to behave "in (ways that vary) with the prevalence of that behavior in that group". For example, a student may influence his friend to get good grades and the friend in turn may induce the student to get good grades.

As noted earlier, we are interested in identifying endogenous effects separately from correlated and contextual effects because of the potential policy implications of positive endogenous effects. In the presence of endogenous effects, policy will have a social multiplier effect. Absent endogenous effects, policy will have no such effect.

\section{Empirical Approach}

Our empirical specification of equation (1) is:

$$
\mathrm{y}_{\text {ist }}=\bar{y}_{\text {ist }} \beta+\mathrm{x}_{\text {is }} \lambda+\delta_{\mathrm{s}}+\varepsilon_{\text {ist }} \text {, }
$$


where $y_{\text {ist }}$ denotes an outcome for individual $i$ in school $s$ at time $t$ and $x_{i s}$ denotes a vector of individual $i$ s observable characteristics or observed heterogeneity, $\delta_{s}$ is a school effect and $\varepsilon_{\text {ist }}$ is a time-variant unobserved component to individual behavior. ${ }^{3} \bar{y}_{i s t}$ denotes the average behavior of individual $\imath$ 's peers. We discuss the construction of $\bar{y}_{i s t}$ in greater detail in section IV. The parameter of interest $\beta$ estimates the extent to which peers influence an individual's behavior. Note that we are deliberately omitting the average peer group background characteristics from equation (3).

Our first set of regressions includes a set of school dummies and a comprehensive set of observed covariates in the regression equation. The inclusion of school fixed effects helps to mitigate endogeneity bias stemming from omitted correlated effects. However, it does not account for any unobserved individual-level heterogeneity within schools that is excluded from $x_{i}$ but also correlated with average group behavior. In addition, the procedure does nothing to solve the biases resulting from the reflection problem. Both of these concerns suggest that this procedure will yield an upper bound on $\beta$.

Our second set of regressions uses average background characteristics of the group member's parents to instrument for average group behavior while controlling for a complete set of school dummies and exogenous covariates. In order to identify equation (3) using instrumental variables estimation, we assume the absence of contextual effects (i.e. $\gamma=0$ ). This type of exclusion restriction is discussed by Manski (1995) and is used quite frequently in the peer effects literature (e.g. Gaviria and Raphael 2001). ${ }^{4}$ The instrumental variables are averages of dummy variables for

\footnotetext{
${ }^{3}$ Note, we include $\delta_{\mathrm{s}}$ in the specification because we believe omitting the school effects will lead to quite serious omitted variables bias. This need not pose any inconsistency between equations (2) and (3) if one includes the school fixed effects in $\mathrm{w}$.

${ }^{4}$ Another practice which is common in this literature is to regress own outcomes on averages of group background characteristics (e.g. Arcidiacono and Nicolson 2005 and Foster 2006). Essentially, this is the reduced form of what we do. Our approach allows for estimates that are more easily interpretable. Provided the identifying assumptions hold, we
} 
whether or not the mothers and fathers of the peer group members have college degrees. We maintain that the educational attainment of the respondent's friends' parents affects his behavior only through his friends' influence and never directly. Though one can certainly conceive of scenarios in which our identifying assumption will break down, we conduct Hansen's J-tests and show that they are reasonable. Meanwhile, the inclusion of the school dummies and exogenous covariates continues to address biases associated with the correlated effects. If either the exclusion restriction or the instruments are invalid, the estimates of $\beta$ will be biased. ${ }^{5}$ Because we expect a positive correlation between the unobserved individual effects and the average background characteristics of peers, the IV estimate of $\beta$ may again be biased upwards.

The estimation is complicated further by potential measurement error in $\bar{y}_{\text {ist }}$. Measurement error in this context comes from two possible sources: reporting errors in peer behaviors and errors in the definition of peer groups. Reporting error refers to the standard measurement error resulting from mistakes in reporting and recording data. The definitional component of measurement error stems from incorrect or imprecise definition of peer groups. In other words, the researcher may define the group to be $G_{i s t}^{*}$ when in reality, the group is $G_{i s t}$. One of the main weaknesses of the peer effects literature is this inability to precisely define the peer group. Manski (1995) states, "Researchers studying social effects rarely offer empirical evidence to support their specifications of reference groups." Definitions of peer groups are often ad-hoc (Appendix A) and depend more on availability of data than a theoretically justified definition of "peers".

identify $\beta$, whereas the other studies identify $\beta \pi$ where $\pi$ denotes the reduced-form relationship between average peer behavior and the contextual effects. Because $\beta \pi$ is harder to interpret than $\beta$, we prefer our approach.

${ }^{5}$ While it is possible, in principle, to estimate the model in first differences while instrumenting for the difference in group behavior with the level of the instrument at baseline as in Arellano Bond (1991), such a procedure is in practice not very useful because these instruments become very weak once the endogenous variable is differenced. 


\section{Defining the Networks}

To better understand the role that network definitions play in the identification of endogenous peer effects, we estimate equation (3) using three different network definitions. Our first definition of the peer group (we call this definition "Friends") uses information from the Add Health friendship network to construct average levels of smoking, drinking, sex, and grade point averages across nominated friends. This definition only includes friends directly nominated by the respondent and is limited to at most five male and five female friends. The summary statistics for average network outcomes are in row 1 of Table 1C. We also report summary statistics for the maximum and minimum of network behavior as defined by $\max _{j}\left\{y_{j s t}: j \in G_{i s t}\right\}$ and $\min _{j}\left\{y_{j s t}: j \in G_{i s t}\right\} .^{6}$

Our second network definition (which we call "Extended Friends") uses all nominated friends from the first definition as well as all friends of nominated friends. Formally, this network is defined as

$$
G_{\text {ist }}^{\mathrm{E}} \equiv\left(\bigcup_{j \in G_{\text {ist }}} G_{j s t}\right) G_{\text {ist }} / \mathrm{i} .
$$

The set $G_{i s t}$ includes all friends from the first network definition. The set $\bigcup_{j \in G_{\text {ist }}} G_{\text {jst }}$ includes all friends of friends. The term / $i$ excludes the individual from his own network. We construct a weighted average over the within group behavior: $\bar{y}_{i s t}=\left(N_{i s t}^{E}\right)^{-1} \sum_{j \in G_{i s t}^{E}} \omega_{j i s t} y_{j s t}$ where $\omega_{j i s t}$ is the number of times that individual $j$ appears in the sets contained in $G_{i s t}^{E}$ and $\mathrm{N}_{\mathrm{ist}}^{\mathrm{E}}=\sum_{\mathrm{j} \in \mathrm{G}_{\mathrm{ist}}^{\mathrm{E}}} \omega_{\mathrm{jist}}$. This

\footnotetext{
${ }^{6}$ Note that because our outcome variable on sexual behavior is binary, we do not report descriptive statistics on its maximum and minimum.
} 
weighting procedure gives more weight to individuals who are "more present" in the extended network.

The averages for $\mathrm{N}_{\text {ist }}^{\mathrm{E}}$ for the In-Home and In-School files are reported in rows two and four of Table 1B. The size of these networks is substantially larger than with the first network definition. In the In-Home data, the average network size goes from 1.27 for the friends network to 4.53 for the extended friends network. In the In-School data, it moves from 3.91 for the friends network to 26.83 for the extended friends network. The summary statistics for the average, maximum and minimum of behaviors in these networks are given in the second row of Table 1C. Note that because the first network definition is a proper subset of this definition, the maxima over these networks get bigger and the minima get smaller.

Our third definition of the peer group is a school-grade cohort. This is the most commonly used definition in the educational peer effects literature. Summary statistics of the mean, max and min of the network behavior are reported in row 3 of Table $1 \mathrm{C}$. When calculating the descriptive statistics for these networks, we again exclude the individual from his own network.

\section{Within Individual Variation in Peer Behavior}

Next, we consider the degree of variation in peer average outcomes within individuals or schools. Without enough variation in outcome variables, standard errors will be high and instrumental variables will be weak. We find that in school fixed-effects regressions, this problem is more pronounced when we define peers as a school-grade cohort and less pronounced when we define peers using friendship ties or extended friendship ties.

In Figures 1 and 2, we calculate the difference between $\bar{y}_{\text {ist }}$ and the school-level or individual-level average of $\bar{y}_{\text {ist }}$. We then plot the non-parametric density estimates of these 
differences for three separate outcome variables: GPA, smoking, and sexual behavior. ${ }^{7}$ Each plot contains three densities each corresponding to the three network definitions: friendship ties, extended friendship ties, and school-grade cohorts. Figure 1 shows the plot of within-individual variation across outcomes and network definitions. We see that for all three outcomes and all three network definitions, there is very little variation. This suggests that a panel data fixed-effects estimator will be inefficient. Therefore, we do not present our results for individual fixed effects regressions and focus on the results from the school fixed effects regressions. In Figure 2, we plot within-school variation and see striking differences across network definitions. Similar to the densities in Figure 1, there is little variation when networks are defined as school-grade cohorts. However, contrary to the densities in Figure 1, there is substantial variation when networks are defined based on friend nominations and extended friendship ties.

The results in Figure 2 raise an interesting issue with using the school-grade cohort definition to estimate peer effects. On one hand, inclusion of school dummies allows researchers to account for the unobserved school-level heterogeneity that is almost certainly correlated with both own and group behavior. On the other hand, it limits variation in the peer group variable substantially and leads to less efficient results and a possible failure to detect endogenous peer effects even when they are present. In other words, tests based on these definitions will have low power.

\section{Results}

Table 2 reports results of the F-tests and associated p-values of a test of the null that the excluded instruments from our IV regressions are significant. Overall the correlations are quite

\footnotetext{
${ }^{7}$ We are unable to provide similar plots for the drinking variable because we require two years of data to calculate the densities. The drinking variable is found in the In-School survey but not in the In-Home survey; it is therefore only available for one year. In contrast, information on GPA, smoking and sexual behavior is available in the two waves of the In-Home survey. This enables us to look at within-individual variation.
} 
high, though they are somewhat less so for the smoking and sex outcome variables. Notably, the instrumental variable is more strongly correlated with average peer group behavior when we use friends and extended friends as the peer group measure and much weaker when we use school-grade cohorts as the peer group measure. Furthermore, using a Hansen's J-test we are unable to reject the null that our instruments are uncorrelated with the structural error term in all cases except one (row 3, column 4). This is a necessary condition for our exclusion restriction to hold. ${ }^{8}$

We report our main regression results in Table 3. ${ }^{9}$ We consider four outcomes: GPA, smoking, sexual behavior and drinking. We report results for two different estimation methods: school fixed effects with individual controls and instrumental variables estimation with school fixed effects and individual controls. Each regression requires data on the individual's own behavior and data on at least one friend in the network. Because of the large degree of missing information in the Add-Health data, these requirements substantially restrict our sample sizes in many cases, especially in the case of regressions using the In-Home data. ${ }^{10}$

Rows 1 and 2 of Table 3 present results for networks defined as friends and extended friends, respectively. We see positive and significant estimates of $\beta$ in all columns though results are weaker for the IV regressions in all cases. For each of the outcome variables, we see that the school

\footnotetext{
${ }^{8}$ Note that if the instruments are valid then the J-test will pass with high probability. The passing of the J-test is necessary, but not sufficient, for the validity of the instrumental variables.

${ }^{9}$ We do not weight our regressions. First, as pointed out by Deaton (1997), unlike in the case with unconditional means, weighting regressions which are conditional means, does not in general recover the weighted average of the regression coefficients across strata. Second, there are missing observations for our weights which will only exacerbate our sample size issues. Third, because there is a substantial amount of missing information in the Add-Health data (see footnote 10), it is possible that the weights are incorrect for the sub-samples of the data on which we run our regressions.

${ }^{10}$ Our sample sizes are small for the following reasons. First, there is a lot of missing data for many of our variables, particularly the parental education variable (See Table 1A). Second, many of the friend reports could not be located in our data because, for example, the friend went to a separate school (See Table 1B). Third, to construct the network averages, we require data on both outcomes and friends' outcomes. Any observations with missing outcomes or friends' outcomes are dropped. Fourth, many of our outcomes are only located in the In-Home data which had substantially fewer observations than the In-School data. Finally, because the In-Home data had smaller sample sizes than the InSchool data, many of the nominated friends could not be located in the In-Home file, even though they could be found in the In-School file.
} 
fixed effects estimates are smaller than the instrumental variables estimates. This is perhaps counterintuitive because we expect the school fixed-effects estimate to be biased by both the reflection problem and individual-level unobserved heterogeneity while the latter should only be biased by individual-level heterogeneity that is correlated with the instrument. However, because of reporting (measurement) errors in the endogenous variable, instrumental variables procedures will eliminate the attenuation bias that is associated with this measurement error and therefore yield larger coefficient estimates. This happens even when there are other sources of bias in the OLS estimates that would bias the OLS results upwards.

Row 3 reports results for regressions using school-grade cohorts as the relevant peer group measure. When we compare these results to those in rows 1 and 2, we see that the school-grade cohort estimates are much weaker than the friends and extended-friends estimates across all outcome variables. In fact, the estimates for sexual behavior and drinking are negative and insignificant. Contrasting this to the positive and significant estimates for friends and extendedfriends networks, we again show the failure of school-grade cohorts to detect positive peer effects. With the exception of the smoking variable, all estimates using the school-grade cohorts are not significant. In comparison to the estimates in rows 1 and 2, these results are also less stable. For example, the school fixed effects estimates for the smoking variable are negative and significant (row 3, column 3), but become positive and significant in the instrumental variables regression (row 3, column 4). Similarly for the drinking variable, the OLS point estimate is positive and the IV point estimate is negative (row 3, columns 7 and 8 ). ${ }^{11}$ Meanwhile, the estimates for friends and extendedfriends peer effects are all positive and highly significant.

We claim the lack of stability in these estimates is symptomatic of the fact that school-grade cohorts are crude approximations of the pupil's actual network. Furthermore, there is far less

\footnotetext{
11 We also examine all of these results broken down by gender but do not see any salient patterns.
} 
within-school variation across school-grade cohorts. In fact, when we plot within-school variation across the three peer-group definitions, we see that school-grade cohorts have strikingly little variation in various peer-average outcomes (see Figure 2). Note that when we plot these same densities for within-individual variation across peer-average outcomes, we do not see this same pattern (see Figure 1). In addition, the instrumental variables estimates in row 3 are particularly weak due to near collinearity of the instruments. The required rank condition is therefore only barely satisfied (Bound, Jaeger and Baker 1995). The crudeness of the school-grade cohort as a definition of peer group and the accompanying lack of sufficient variation in the peer-average outcome variables lead to lack of stability and precision in estimates of school-grade cohort peereffects.

This raises an additional concern in the use of school-grade cohorts as a measure of peer group. The definition of the peer group by the school-grade cohort precludes using both school dummies and instrumental variables that only vary at the school level. As a result, researchers face a difficult choice between addressing the school-level correlated effects but not the reflection problem, addressing the reflection problem but not the school-level correlated effects or addressing both but falling victim to weak instruments. In contrast, the use of the two definitions based on the Add-Health friend files allows us to address both the reflection problem and the school-level correlated effects without falling prey to weak instruments.

Next, we compare rows 1 and 2 of Table 3. We see that for all four outcome variables, the estimates using the extended-friend networks are larger than those using the smaller friend networks. These results indicate the presence of non-linearities in peer effects. For example, extending the network may include additional pupils in the network who are not directly friends with the respondents but who, nevertheless, provide further avenues of influence. These non-linearities deserve further analysis but are not probed here. 


\section{Conclusions}

In this paper, we explore the role of peer group definitions in the estimation of endogenous peer effects in GPA, smoking, sexual behavior, and drinking using the National Longitudinal Adolescent Health Survey. Under appropriate identifying assumptions we provide evidence of endogenous peer effects in school performance and the propensity to smoke, have sex, and drink. But we also find that the magnitudes, precision, and stability of estimates differ quite widely depending on the definition of peer groups. Furthermore, we provide evidence that errors in defining the peer network correctly may lead to underestimates of peer effects in many contexts. Because definition of peer groups is often ad-hoc in the existing literature, we find these results highlight the need to justify use of particular definitions.

In particular, we contend that the use of school-grade cohorts as the definition of peer network in the school peer-effects literature is problematic. We claim that estimates based on the school-grade cohorts are essentially reduced-form approximations of a two-step process in which students first sort themselves into friend groups and then choose behaviors which lead to outcomes. Though it may be true that school-grade cohorts are the policy tool over which policymakers have the most control, it is untrue that policy based on estimates of peer-effects at the school-grade cohort level will be most effective. Due to the lack of a canonical model describing how students choose friends, it is unclear whether estimates of a linear model based on school-grade cohorts provide an adequate approximation of the more complicated process. However, in order for researchers to determine if school-grade cohort effects provide an adequate approximation, it is necessary to compare these to peer effects estimates based on actual peer networks. Our work presents a first step in this direction. 
Appendix A. Peer group definitions in the education literature.

\begin{tabular}{|l|l|}
\hline Study & Definition of Peer Group \\
\hline Gaviria and Raphael, 2001 & School cohorts \\
\hline Angrist and Lang, 2004 & School-grade cohorts \\
\hline Arcidiacono and Nicholson, 2005 & School-grade cohorts \\
\hline Carrell, Malmstrom and West, 2007 & School-grade cohorts \\
\hline Hanushek, Markman, Kain and Rivkin, 2001 & School-grade cohorts \\
\hline Hoxby, 2000 & School-grade cohorts \\
\hline Lavy, Paserman, and Schlosser, 2007 & School-grade cohorts \\
\hline Burke and Sass, 2006 & Classroom \\
\hline Vigdor and Nechbya, 2004 & Classroom \\
\hline Duncan et al, 2005 & Roommates \\
\hline Sacerdote, 2001 & Roommates \\
\hline Foster, 2006 & $\begin{array}{l}\text { Residents of same wing of a } \\
\text { residence hall floor }\end{array}$ \\
\hline Carrell, Fullerton, Gilchrist, and West, 2007 & Squadron \\
\hline
\end{tabular}




\section{References}

Aizer, Anna and Janet Currie, (2004). "Networks or neighborhoods? Correlations in the use of publicly-funded maternity care in California," Journal of Public Economics, 88: 2573-2585.

Angrist, Joshua D. and Kevin Lang, (2004). "Does school integration generate peer effects? Evidence from Boston's Metco Program,” American Economic Review, 94(5).

Arcidiacono, Peter and Sean Nicholson, (2005). "Peer effects in medical school," Journal of Public Economics, 89: 327-350.

Arellano, Manuel and Steven Bond, (1991). "Some Tests of Specification for Panel Data: Monte Carlo Evidence and an Application to Employment Equations," Review of Economic Studies, 58, 277 297.

Bedard, Kelly and Chau Do, (2005). "Are middle schools more effective? The impact of school structure on student outcomes," Journal of Human Resources, 40(3): 660-682.

Bobonis, Gustavo J. and Frederico Finan, (2006). "Endogenous peer effects in school participation," unpublished manuscript.

Bound, John, Jaeger, David and Regina Baker (1995). "Problems with Instrumental Variables Estimation when the Correlation Between the Instruments and Endogenous Explanatory Variable is Weak," Journal of the American Statistical Association, 90: 443-450.

Burke, Mary A. and Tim R. Sass, (2006). "Classroom peer effects and student achievement," unpublished manuscript.

Carrell, Scott E., Frederick Malmstrom, and James E. West, (2008). "Peer Effects in Academic Cheating," forthcoming Journal of Human Resources.

Carrell, Scott E., Richard L. Fullerton, and James E. West, (2007). "Estimating Academic Peer Effects: The Importance of Knowing the Relevant Peer Group," Working Paper.

Cipollone and Rosolia, (2007). "Social Interactions in High School: Lessons from an Earthquake," American Economic Review, 97(3): 948-965.

Cullen, Julie Berry, Brian A. Jacob, and Steven D. Levitt, (2006). "The Effect of School Choice on Participants: Evidence From Randomized Lotteries,” Econometrica 74(5):1191-1230.

Deaton, Angus, (1997). "The Analysis of Household Surveys: A Microeconometric Approach to Development Policy," The Johns Hopkins University Press.

Dodge, Kenneth A., Thomas J. Dishion, and Jennifer E. Lansford, (2006). "Deviant Peer Influences in Intervention and Public Policy for Youth," Social Policy Report, Society for Research in Child Development. 
Duflo, Esther and Emmanuel Saez, (2002). "The Role of Information and Social Interactions in Retirement Plan Decisions: Evidence from a Randomized Experiment," Quarterly Journal of Economics 118(3): 815-842.

Duncan, Greg J., Johanne Boisjoly, Michael Kremer, Dan M. Levy, and Jacque Eccles, (2005). "Peer Effects in Drug Use and Sex Among College Students," Journal of Abnormal Child Psychology, 33(3): 375-385.

Foster, Gigi, (2006). "It's Not Your Peers, and It's Not Your Friends: Some Progress Toward Understanding the Educational Peer Effect Mechanism," Journal of Public Economics 90: 1455-1475.

Gaviria, Alejandro and Steven Raphael, (2001). "School-based peer effects and juvenile behavior," The Review of Economics and Statistics, 83(2): 257-268.

Hanushek, Eric A., John F. Kain, Jacob M. Markman, and Steven G. Rivkin, (2003). "Does peer ability affect student achievement?" Journal of Applied Econometricts 18(5): 527-544.

Hanushek, Eric A., John F. Kain, and Steven G. Rivkin, (2002). "Inferring Program Effects For Special Populations: Does Special Education Raise Achievement For Students With Disabilities?" Review of Economics and Statistics, 84(4): 584-599.

Hoxby, Caroline, (2000). "Peer Effects in the Classroom: Learning from Gender and Race Variation," NBER Working Paper 7867.

Kremer, Michael and Dan Levy, (2003). "Peer Effects and Alcohol Use Among College Students," NBER Working Paper 9876.

Lavy, Victor, Analia Schlosser, and M. Daniele Paserman (2007). "Inside the Black Box of Ability Peer Effects: Evidence from Variation in High and Low Achievers in the Classroom" unpublished manuscript.

Lefgren, Lars, (2004). "Educational Peer Effects and the Chicago Public Schools." Journal of Urban Economics, 56(2): 169-191.

Mas, Alexandre and Enrico Moretti, (2006). "Peers at work," NBER Working Paper 12508.

Manski, Charles F., (1995). "Identification Problems in the Social Sciences," Harvard University Press.

Mayer, Adalbert and Steven L. Puller, (2006). "The old boy (and girl) network: social network formation on university campuses," forthcoming Journal of Public Economics.

Sacerdote, Bruce, (2001). "Peer Effects with Random Assignment: Results for Dartmouth Roommates," Quarterly Journal of Economics, 116(2): 681-704.

Sacerdote, Bruce and David Marmaros, (2006). "How do Friendships Form?” Quarterly Journal of Economics 121(1): 79-119. 
Whitmore, Diane, (2005). "Resource and Peer Impacts on Girls' Academic Achievement: Evidence from a Randomized Experiment," American Economic Review, 95(2):199-203. 
Table 1A. Summary Statistics

\begin{tabular}{|c|c|c|c|}
\hline Variable (Survey) & $\begin{array}{l}\text { Average for } \\
\text { all adolescents }\end{array}$ & Variable & $\begin{array}{l}\text { Average for all } \\
\text { adolescents }\end{array}$ \\
\hline Age (School) & $\begin{array}{l}15.00 \\
(1.71) \\
\mathrm{N}=85266\end{array}$ & $\begin{array}{l}\text { Self-Reported Health } \\
\text { Status (School) }\end{array}$ & $\begin{array}{l}2.09 \\
(0.94) \\
\mathrm{N}=814333\end{array}$ \\
\hline Black (School) & $\begin{array}{l}.19 \\
(.39) \\
\mathrm{N}=85626\end{array}$ & GPA (School) & $\begin{array}{l}2.86 \\
(.79) \\
N=54135\end{array}$ \\
\hline White (School) & $\begin{array}{l}.61 \\
(.49) \\
\mathrm{N}=85626\end{array}$ & \# cigs per day (Home) & $\begin{array}{l}4.30 \\
(7.14) \\
N=13555\end{array}$ \\
\hline Male (School) & $\begin{array}{l}.50 \\
(.50) \\
\mathrm{N}=84988\end{array}$ & Ever have sex (Home) & $\begin{array}{l}0.40 \\
(0.49) \\
N=33804\end{array}$ \\
\hline $\begin{array}{l}\text { Mother's education }{ }^{1} \\
\text { (School) }\end{array}$ & $\begin{array}{l}.32 \\
(.47) \\
N=66815\end{array}$ & $\begin{array}{l}\text { \# days drank last year } \\
\text { (School) }\end{array}$ & $\begin{array}{l}20.44 \\
(59.18) \\
N=79824\end{array}$ \\
\hline $\begin{array}{l}\text { Father's education }{ }^{1} \\
\text { (School) }\end{array}$ & $\begin{array}{l}.38 \\
(.49) \\
N=54010\end{array}$ & & \\
\hline
\end{tabular}

Notes: Standard deviations in parentheses.

This table summarizes network information for the in-school and in-home samples.

${ }^{1}$ Indicator for whether or not parent has a college education.

Table 1B. Average numbers of friends in the network

\begin{tabular}{llll}
\hline \hline & $\begin{array}{l}\text { Network } \\
\text { Definition }\end{array}$ & $\begin{array}{l}\text { Average Friend } \\
\text { Number }\end{array}$ & $\begin{array}{l}\text { Number of Observations } \\
\text { with One or More } \\
\text { Nominated Friends }\end{array}$ \\
\hline In-Home & Friends & $\begin{array}{l}1.27 \\
(1.67)\end{array}$ & 21118 \\
In-Home & Extended & $\begin{array}{l}4.53 \\
(8.97)\end{array}$ & 21118 \\
In-School & Friends & $\begin{array}{l}3.91 \\
(3.10)\end{array}$ & 66308 \\
& Friends & 26.83 & 66308 \\
In-School & Extended & $(24.72)$ & \\
& Friends & & \\
\hline
\end{tabular}


Table 1C: Peer Group Averages

\begin{tabular}{|c|c|c|c|c|c|c|c|c|c|c|}
\hline & (In- & $\begin{array}{l}\text { GPA } \\
\text { chool S }\end{array}$ & rvey) & $\begin{array}{l}\text { \# } \\
\text { (In- }\end{array}$ & $\begin{array}{l}\text { ligs Per } \\
\text { Home Su }\end{array}$ & $\begin{array}{l}\text { ay } \\
\text { vey) }\end{array}$ & $\begin{array}{l}\text { \# Day } \\
\text { (In- }\end{array}$ & $\begin{array}{l}\text { Drank La } \\
\text { chool Su }\end{array}$ & $\begin{array}{l}\text { st Year } \\
\text { vey) }\end{array}$ & $\begin{array}{l}\text { Ever Have Sex? } \\
\text { (In-Home Survey) }\end{array}$ \\
\hline \multirow{3}{*}{ Friends } & Mean & Max & Min & Mean & Max & Min & Mean & $\operatorname{Max}$ & Min & Mean \\
\hline & 2.91 & 3.39 & 2.36 & 4.13 & 5.75 & 2.92 & 19.91 & 63.51 & 3.37 & 0.40 \\
\hline & $(0.59)$ & $(0.64)$ & $(0.76)$ & $(6.37)$ & $(8.83)$ & $(5.81)$ & $(35.17)$ & (99.01) & $(22.17)$ & $(0.44)$ \\
\hline \multirow[t]{2}{*}{ Extended Friends } & 2.92 & 3.74 & 1.80 & 3.88 & 8.14 & 1.75 & 20.52 & 155.38 & 0.95 & 0.41 \\
\hline & $(0.46)$ & $(0.45)$ & $(0.66)$ & $(5.40)$ & (11.39) & $(4.24)$ & $(24.86)$ & (137.64) & (13.05) & $(0.40)$ \\
\hline School-Grade & 2.84 & 3.99 & 1.14 & 3.52 & 19.70 & 0.08 & 19.86 & 339.87 & 0.18 & 0.38 \\
\hline Cohort & $(0.30)$ & $(0.08)$ & $(0.30)$ & $(2.25)$ & $(17.68)$ & $(0.81)$ & $(10.56)$ & (73.12) & (7.91) & $(0.20)$ \\
\hline
\end{tabular}


Table 2. First-Stage Correlations.

\begin{tabular}{lllll}
\hline \hline & GPA & Smoking & Sex & Drinking \\
\hline Friends & 182.31 & 1.46 & 4.39 & 19.01 \\
& {$[0.000]$} & {$[0.2377]$} & {$[0.0145]$} & {$[0.000]$} \\
Extended & 170.85 & 9.61 & 2.61 & 14.00 \\
Friends & {$[0.000]$} & {$[0.0001]$} & {$[0.0779]$} & {$[0.000]$} \\
School-Grade & 12.81 & 4.66 & 1.54 & 0.08 \\
Cohorts & {$[0.000]$} & {$[0.0112]$} & {$[0.2182]$} & {$[0.9210]$} \\
\hline
\end{tabular}

Note: Each cell of this table reports the F-test and associated p-value in brackets of a test of the null that the excluded instruments from our IV regressions are significant in the first state regressions. All regressions include all of the exogenous covariates from the main regression equation.

Table 3. Average Peer Effects

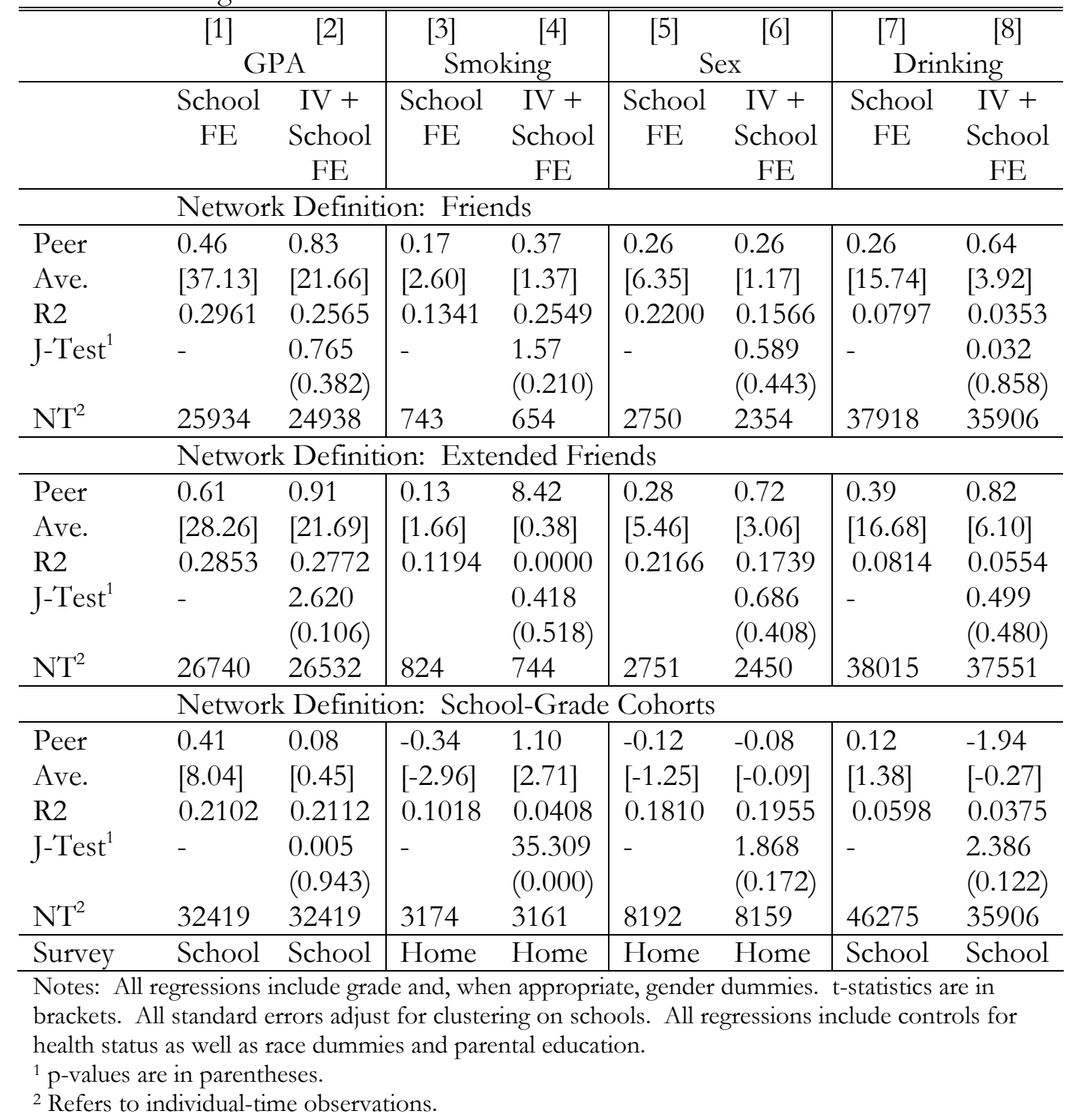


Figure 1. Within-individual variation in GPA, Sex, Smoking
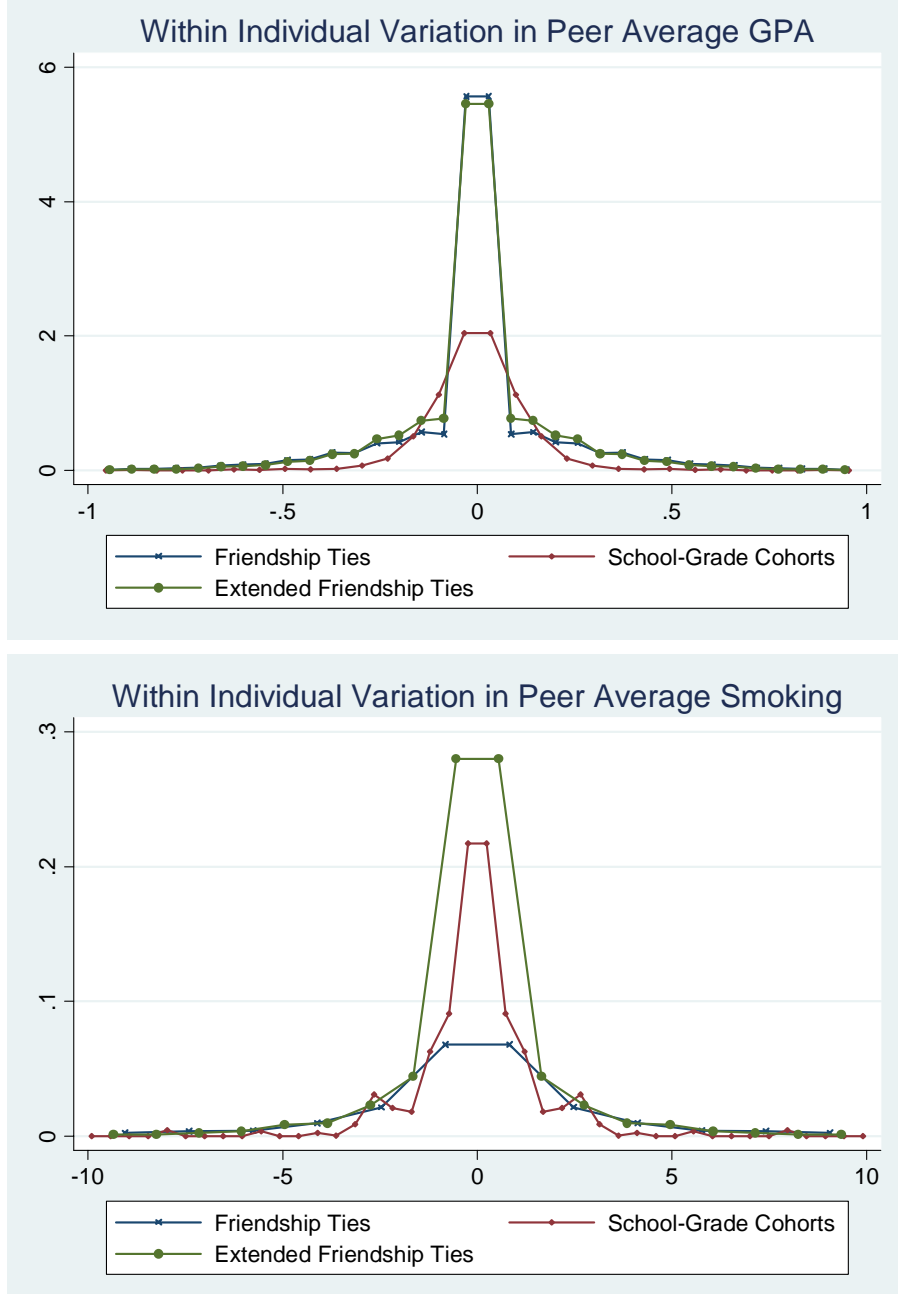

Within Individual Variation in Peer Average Sexual Behavior

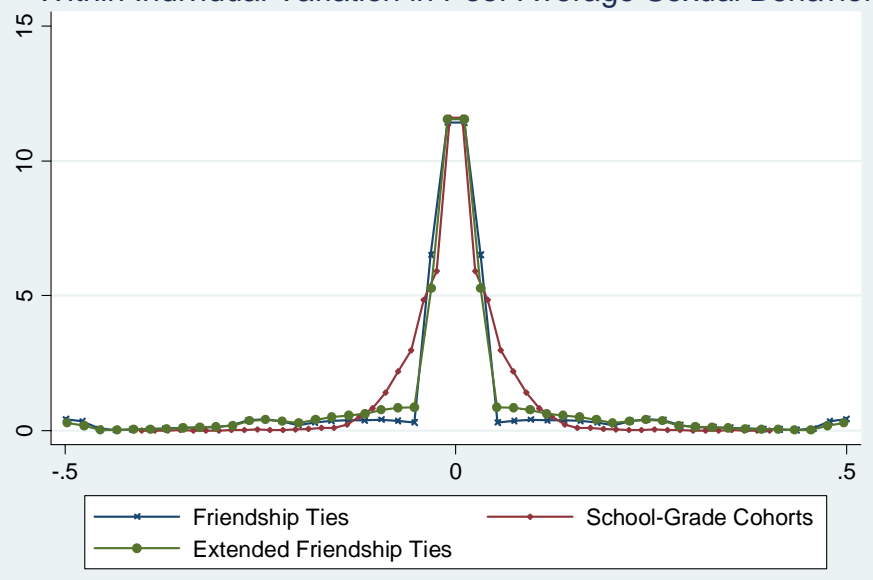

Note: We are unable to provide similar plots for the drinking variable because we require two years of data to calculate the densities. The drinking variable is found in the In-School survey but not in the In-Home survey; it is therefore only available for one year. In contrast, information on GPA, smoking and sexual behavior is available in the two waves of the In-Home survey. This enables us to look at within-individual variation. 
Figure 2. Within-school variation in GPA, Sex, Smoking
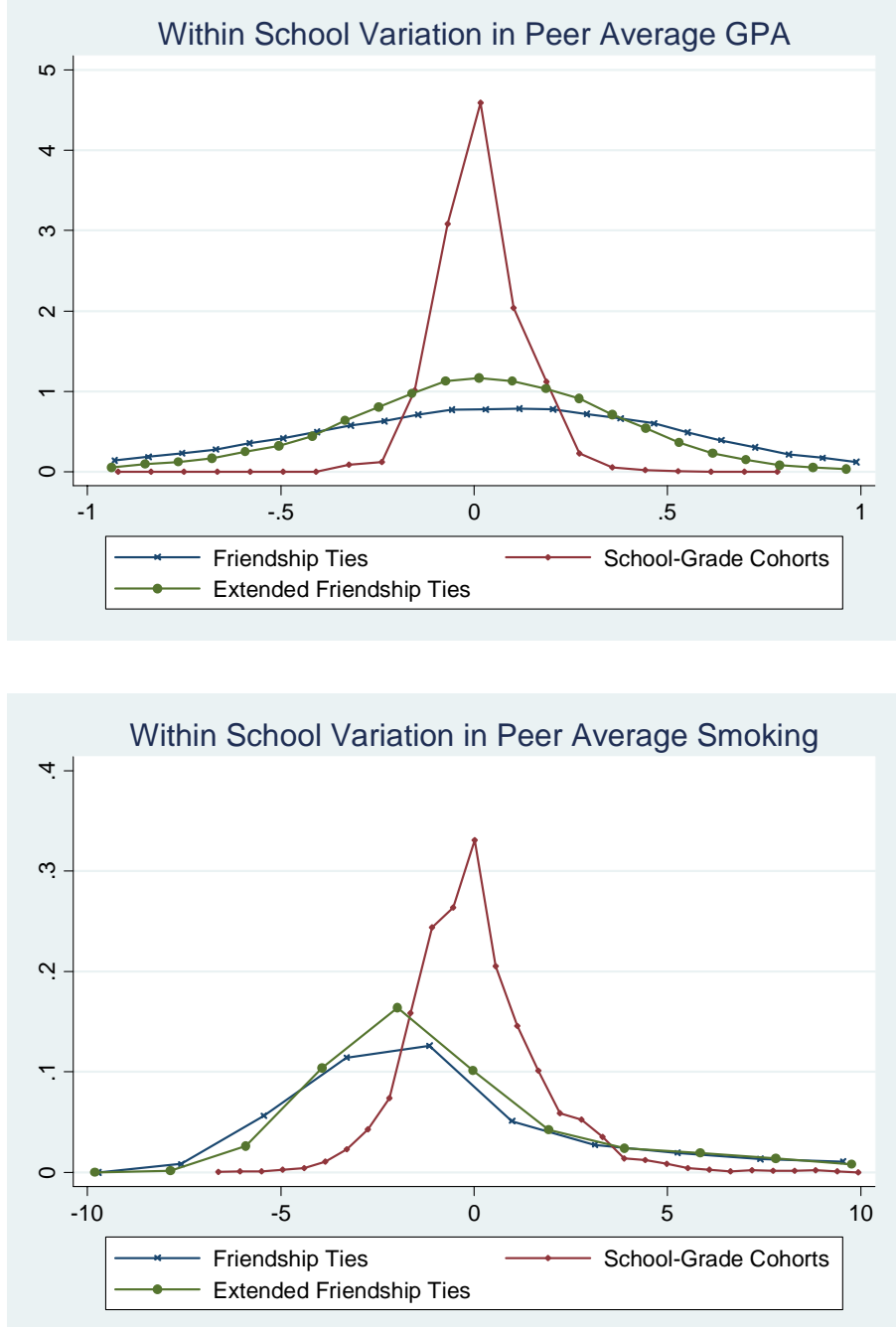

Within School Variation in Peer Average Sexual Behavior

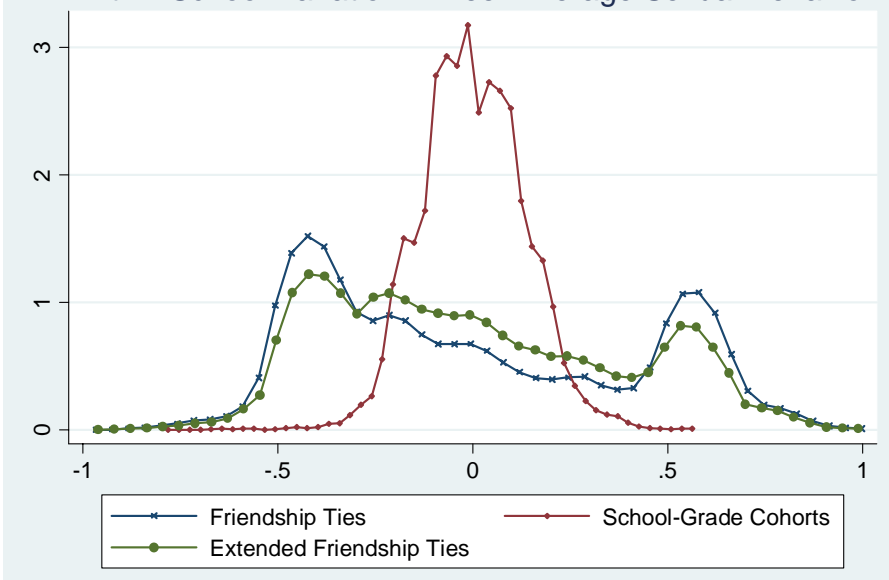

